Invited Research Article

\title{
Indian summer monsoon variability over last 2000 years inferred from sediment magnetic characteristics in Lugu Lake, southwest China
}

\author{
Xiaohui Wang ${ }^{\mathrm{a}}$, Longsheng Wang ${ }^{\mathrm{a}, \mathrm{b}, \mathrm{c}, \mathrm{d}, *}$, Shouyun $\mathrm{Hu}^{\mathrm{b},{ }^{* *}}$, Mingming Ma ${ }^{\mathrm{e}}$, Qing Wang ${ }^{\mathrm{a}}$, \\ Buli Cui ${ }^{a}$, Chao Zhan ${ }^{a}$, Lin Zeng ${ }^{\mathrm{a}}$, Xianbin Liu ${ }^{\mathrm{a}}$, Ji Shen ${ }^{\mathrm{b}}$ \\ ${ }^{\text {a }}$ Coast Institute of Ludong University, Yantai 264025, China \\ ${ }^{\mathrm{b}}$ State Key Laboratory of Lake Science and Environment, Nanjing Institute of Geography and Limnology, Chinese Academy of Sciences, Nanjing 210008, China \\ ${ }^{\mathrm{c}}$ CAS Key Laboratory of Coastal Environmental Processes and Ecological Remediation, Yantai Institute of Coastal Zone Research, Chinese Academy of Sciences, Yantai \\ 264003, China \\ ' State Key Laboratory of Loess and Quaternary Geology, Institute of Earth Environment, Chinese Academy of Sciences, Xi'an 710061, China \\ ${ }^{\mathrm{e}}$ Institute of Geography, Fujian Normal University, Fuzhou 350007, China
}

\section{A R T I C L E I N F O}

\section{Editor: Paul Hesse}

\section{Keywords:}

Environmental magnetism

Rock Magnetism

Monsoon precipitation

Catchment erosion

Lake sediment

\begin{abstract}
A B S T R A C T
Knowledge of climatic change during the past 2000 years in southwestern China is important for understanding the evolution of the Indian summer monsoon (ISM). For this study, we conducted systematic analysis of magnetic minerals in sediments from Lugu Lake in northwestern Yunnan Province. Magnetic measurements suggest that magnetite dominated the studied magnetic mineral assemblages. Both natural origins and anthropogenic activities are considered to be the sources of the magnetic minerals based on the correlations of $\chi \mathrm{vs} . \chi_{\mathrm{fd}} \%$ and $\chi_{\mathrm{ARM}} / \chi$. The magnetic minerals of natural origins can be attributed to terrestrial detrital input rather than biogenic sources. Combined with diatom and geochemical records, magnetic parameters including $\chi, \chi_{\mathrm{fd}} \%$, and $S$. ratio can be used as sensitive indicators of ISM change, and suggest that two significant dry periods occurred in the Medieval Warm Period (MWP, 800-1300 CE) and Roman Warm Period (RWP, 0-400 CE) and two relatively wet intervals in the Dark Ages Cold Period (DACP, 400-800 CE) and Little Ice Age (LIA, 1300-1850 CE). Significant shifts of magnetic parameters in Lugu Lake samples revealed sensitivity to precipitation-controlled catchment erosion. The climatic patterns shown by the magnetic characteristics were generally similar to those in extensive areas dominated by the ISM. We speculate that rainfall caused by the ISM during the last 2000 years may be related to the variations of El Niño/Southern Oscillation (ENSO) and the mean position migration of the ITCZ.
\end{abstract}

\section{Introduction}

Understanding of paleoenvironmental change in the past 2000 years is important for investigating global climate dynamics. The past 2000 years of environmental change included the period of environmental change dominated by natural conditions before $1800 \mathrm{CE}$ and that dominated by natural and anthropogenic influence after $200 \mathrm{CE}$, which is also a period for which historical documents and natural environmental records coexist (Ge et al., 2013a). Many environmental records show that precipitation and temperature variations in the Northern Hemisphere over the past 2000 years generally followed similar trends on centennial timescales. The environmental and climatic events during the past 2000 years mainly included the Roman Warm Period (RWP,
0-400 CE), the Dark Ages Cold Period (DACP, 400-800 CE), the Medieval Warm Period (MWP, 800-1300 CE), the Little Ice Age (LIA, 1300-1850 CE), and the Current Warm Period (CWP, 1850 CE-present) (Lamb, 1977). Proxy-derived temperature records have revealed significant temporal and spatial differences in the last 2000 years (Diaz et al., 2011; Graham et al., 2011; Yan et al., 2011; Chen et al., 2015; Dixit and Tandon, 2016; Gu et al., 2020). This variability might be related to the spatiotemporal patterns of changes in atmospheric circulation (An et al., 2015). To understand the driving forces of hydrologic and climate changes in this region, it is important to first reconstruct the paleoenvironmental changes of different areas over the last 2000 years using empirical data from specific locations.

The Asian summer monsoon (ASM), including the westerlies from

\footnotetext{
* Corresponding author at: Coast Institute of Ludong University, Yantai 264025, China.

$* *$ Corresponding author.

E-mail addresses: 52wls@163.com (L. Wang), hu_shouyun@hotmail.com (S. Hu).
} 

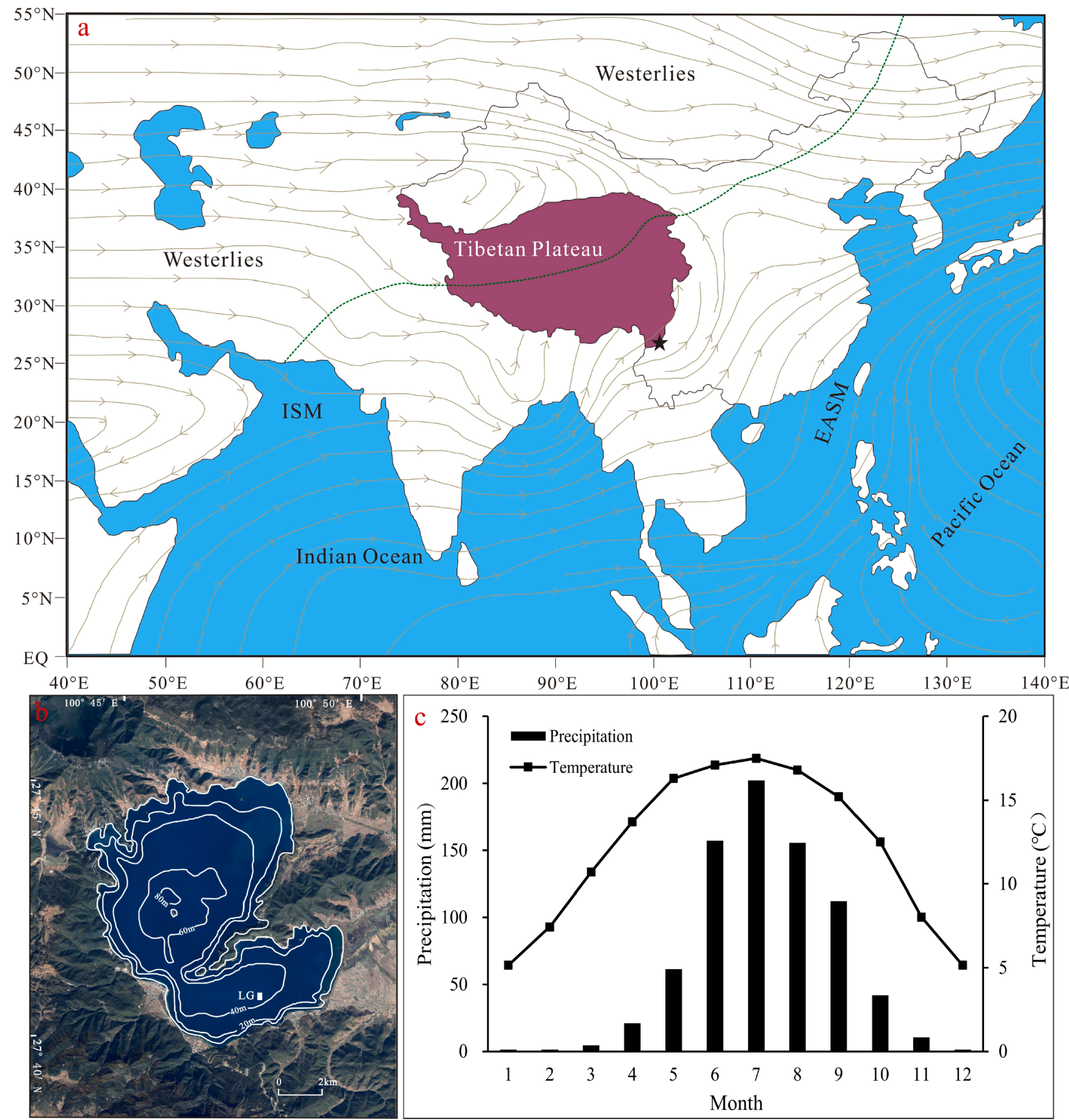

Fig. 1. Map showing a summer mean $700 \mathrm{hPa}$ streamline based on the NCEP/NCAR reanalysis during 1971-2000. Black pentagram indicates the location of Lugu Lake. EASM, ISM, and Westerlies represent the East Asian Summer Monsoon, Indian Summer Monsoon, and Westerlies, respectively. b Lake bathymetry and coring site (solid rectangle). c Climate diagram from the meteorological station in Yanyuan, Sichuan Province $\left(27^{\circ} 25^{\prime} \mathrm{N}, 101^{\circ} 30^{\prime} \mathrm{E} ; 2540 \mathrm{~m}\right.$ above sea level), near Lugu Lake, showing monthly temperature and precipitation data. These data are 62-year climate averages for the period from 1951 to 2012 from the Yanyuan weather station, China Meteorological Data Sharing Service Platform, http://cdc.cma.gov.cn.

inner Asia, the Indian summer monsoon (ISM) from the Indian Ocean, and the East Asian summer monsoon (EASM) from the Pacific Ocean, plays an important role in transporting moisture and heat from the tropical oceans to the higher latitudes of Asia (An et al., 2000) (Fig. 1a). Changes of monsoonal precipitation can lead to extreme floods or droughts, affecting more than $60 \%$ of the world's population in most areas of East and South Asia (Wang, 2006). Some studies have shown that ASM intensity and related precipitation changes are closely related to the prosperity and decline of ancient human civilizations ( $\mathrm{Wu}$ and
Liu, 2004; Dixit et al., 2014). Therefore, it is important to understand the mechanisms and possible driving forces of monsoon changes on different time scales. Several studies have focused on the variations of the ASM over the past 2000 years using marine sediment records (Agnihotri et al., 2002; Anderson et al., 2002), tree ring records (Cook et al., 2010; Sano et al., 2011; He et al., 2013), lake sediment records (Liu et al., 2011; Sheng et al., 2015; Cui et al., 2018; Feng et al., 2019), stalagmite records (Zhang et al., 2008; Tan et al., 2019), and historical literature (Zheng et al., 2006; Tan et al., 2008; Chen et al., 2019). These 


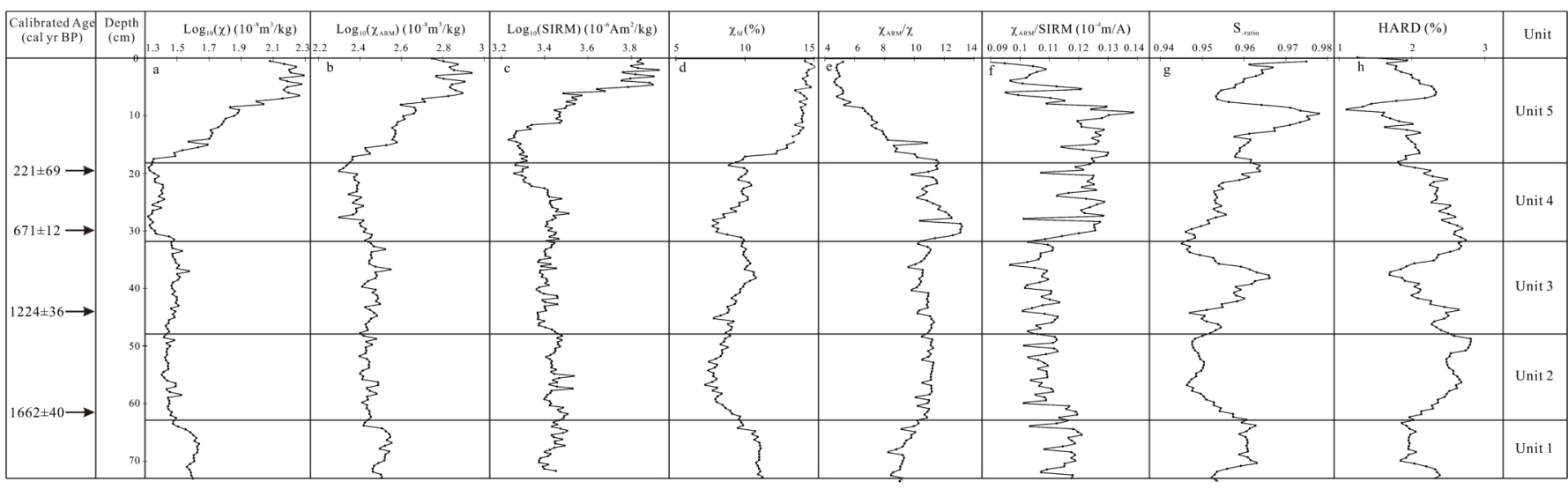

Fig. 2. Comprehensive profile of Lugu Lake sediments including AMS ${ }^{14} \mathrm{C}$ age (Wang et al., 2020), magnetic parameters and sedimentary units.

studies have shown ASM intensity over decadal to centennial scales in the last 2000 years.

Lugu Lake is located on the southeast edge of the Qinghai-Tibet Plateau in Southwest China. The lakes in this area are tectonic lakes with fragile ecosystems, and can respond to environmental changes on scales from decades to millions of years (Chen et al., 2014; Wang et al., 2019). Magnetic measurement is a rapid, intensive, and non-destructive method to characterize high-resolution mineralogical changes, and is widely used in marine sequence comparison, paleoclimate, and provenance research (Peters et al., 2010; Chang et al., 2016; Wang et al., 2018a, 2018b) on lacustrine (Hu et al., 2015; Xu et al., 2020) and aeolian sediments (Gao et al., 2018). Magnetic mineralogy has become one of the most important proxies in paleoenvironmental and paleoclimatic reconstruction (Su et al., 2013; Lise-Pronovost et al., 2014). However, because authigenesis/diagenesis and biogenesis after deposition can influence the concentrations and grain size of magnetic minerals in lacustrine sediments, and even form new magnetic minerals. (Hu et al., 2015; Wei et al., 2018). How to reveal sensitive slow-scale (decadal to centennial scale) climatic and paleoenvironmental events using magnetic parameters remains undetermined and is a problem of urgent concern. Therefore, in this study, we systematically investigated the magnetic characteristics of sediments from Lugu Lake deposited in the past 2000 years. First, variations of the magnetic mineral assemblages with respect to age were evaluated. Second, we examined the sources of magnetic minerals and the relationship between magnetic parameters and precipitation-controlled catchment erosion. Then, the responses of sediment magnetic properties to the ISM and possible driving forces of ISM variability were explored.

\section{Regional setting}

Lugu Lake $\left(100^{\circ} 45^{\prime}-100^{\circ} 50^{\prime} \mathrm{E}, 27^{\circ} 41^{\prime}-27^{\circ} 45^{\prime} \mathrm{N}\right)$ is located in southwestern Sichuan Province and northwestern Yunnan Province on the southeastern edge of the Qinghai-Tibet Plateau (Fig. 1b). It's a semiclosed lake with a maximum water depth of $93.5 \mathrm{~m}$ and a mean depth of $40.3 \mathrm{~m}$. It has a surface area of $48.45 \mathrm{~km}^{2}$, and a catchment drainage area of $171.4 \mathrm{~km}^{2}$ (Wang and Dou, 1998). Lugu Lake is fed hydrologically by rainfall, seasonal inflow, and surface runoff. The Gaizu River, which is the only outlet of Lugu Lake, is connected with the lake by the Caohai wetland (Wang et al., 2018a, 2018b). The basin bedrock is mainly composed of sandstone, limestone, and mudstone. Soils in the catchment of Lugu Lake include mainly Mollisols, Alfisols, Entisols, and Oxisols (Zhang et al., 1997). The study area is characterized by a typical monsoon climate with distinct wet and dry seasons. The region is mainly affected by warm and humid airflow from the Bay of Bengal in summer, the southern branch of the westerlies in winter, and the local climate over the Qinghai-Tibet Plateau. The average annual temperature is $12.8^{\circ} \mathrm{C}$, with average temperatures of $5.6^{\circ} \mathrm{C}$ in January and $19.4{ }^{\circ} \mathrm{C}$ in
July. The mean annual rainfall is $900 \mathrm{~mm}$, and summer precipitation from June to September accounts for $80 \%$ of the annual precipitation (Fig. 1c).

\section{Sampling and methods}

Seven sediment cores (LGS) $\left(27^{\circ} 41^{\prime} 48^{\prime \prime} \mathrm{N}, 100^{\circ} 48^{\prime} 5^{\prime \prime} \mathrm{E}\right)$ were collected from a water depth of $42.5 \mathrm{~m}$ in the southeast basin of Lugu Lake using an Austrian UWITEC Gravity Corer in June 2012 (Fig. 1b). The core sites were at intervals of $1 \mathrm{~m}$, and the cores stratigraphically overlapped. Cores LGS-1, LGS-2, and LGS-4 were subsampled at $0.5 \mathrm{~cm}$ intervals. Core LGS-4 (length: $98 \mathrm{~cm}$ ) was used for magnetic measurement. Core LGS-1 (length: $104 \mathrm{~cm}$ ) was used for pigment and cladoceran measurement. Core LGS-2 (length: $93.5 \mathrm{~cm}$ ) was used for grain-size, diatom, and geochemical analysis. In addition, to provide appropriate samples for ${ }^{210} \mathrm{~Pb}$ and ${ }^{137} \mathrm{Cs}$ dating, core LGS-7 (a short sediment core), with a clear mud-water interface, was obtained and squeezed at $0.5 \mathrm{~cm}$ sections. All the subsamples were collected into numbered plastic bags, placed in a refrigerator at $4{ }^{\circ} \mathrm{C}$, and immediately returned to the laboratory for further analysis.

The age-depth model was established using radiometric ${ }^{210} \mathrm{~Pb},{ }^{137} \mathrm{Cs}$, and accelerator mass spectrometry (AMS) ${ }^{14} \mathrm{C}$ dating. The activities of ${ }^{210} \mathrm{~Pb}$ and ${ }^{137} \mathrm{Cs}$ were measured at the Nanjing Institute of Geography and Limnology, Chinese Academy of Sciences. AMS dating of bulk organic sediments may be affected by the reservoir effect of 'old' carbon, which can cause significant uncertainty in age models (Hou et al., 2012). In this study, we used terrestrial plant remains to establish a reliable age model (Grimm et al., 2009). Six samples of terrestrial plant remains were collected along the entire core (Wang et al., 2020). The AMS ${ }^{14} \mathrm{C}$ analyses were performed at the Beta Radiocarbon Analytic Laboratory (Miami, FL, USA). All AMS ${ }^{14} \mathrm{C}$ dates were calibrated to calendar years (0 yr BP $=1950 \mathrm{CE}$ ) using the IntCal13 calibration dataset and the program Calib 7.1 (Reimer et al., 2013).

Magnetic susceptibility was measured using an AGICO MFK-1 Kappabridge susceptometer at 976 and $15,616 \mathrm{~Hz}$ and was then normalized by mass $\left(\chi_{\mathrm{lf}}\right.$ and $\left.\chi_{\mathrm{hf}}\right)$. Frequency-dependent susceptibility $\left(\chi_{\mathrm{fd}}\right)$ was calculated using the formula $\chi_{\mathrm{fd}}(\%)=\left[\left(\chi_{\mathrm{lf}}-\chi_{\mathrm{hf}}\right) / \chi_{\mathrm{lf}}\right] \times 100$. Anhysteretic remanent magnetization (ARM) was imparted with a peak alternating field of $100 \mathrm{mT}$ and a direct current bias field of $0.05 \mathrm{mT}$ using a long-core cryogenic magnetometer (2-G Enterprises Model 755-1.65UC). The ARM susceptibility ( $\chi_{\text {ARM }}$ ) was obtained by dividing the ARM intensity by the DC field strength. Isothermal remanent magnetization (IRM) was imparted using an MMPM9 pulse magnetizer and measured with a Molspin Minispin magnetometer. The IRM at $1 \mathrm{~T}$ was considered the saturation IRM (SIRM), then applied a $300 \mathrm{mT}$ reverse field $\left(\mathrm{IRM}_{-300 \mathrm{mT}}\right)$, and calculated the hard isothermal remanent magnetization (HARM) by $\left.\left(\mathrm{SIRM}_{+} \mathrm{IRM}_{-300 \mathrm{mT}}\right) / 2\right)$ and $\mathrm{S}_{\text {-ratio }}$ by (IRM. $300 \mathrm{mT} / \mathrm{SIRM}$ ). HARD $\%$ that reflected the relative concentrations of hard 


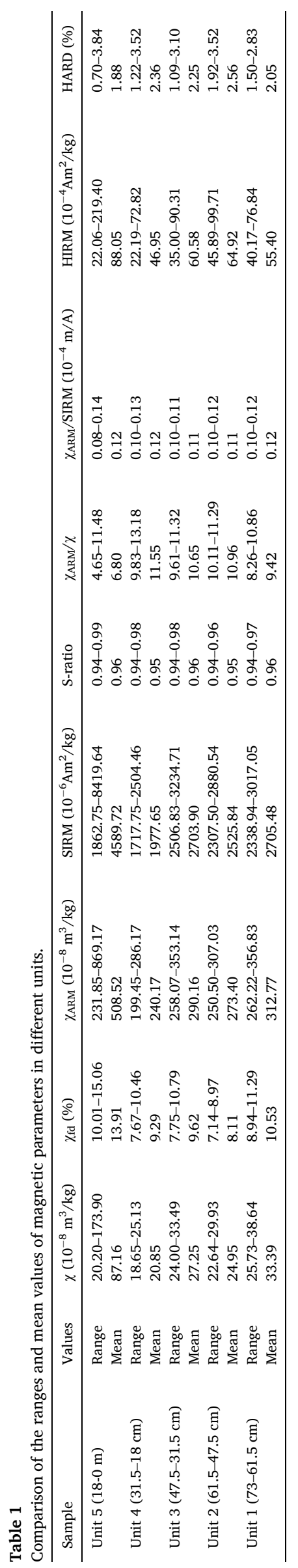

magnetic minerals were calculated using the formula HARD $=($ HIRM/ SIRM) $\times 100$. In addition, some representative samples selected based on the above magnetic parameters were used to measure hightemperature $\kappa-T$ curves, IRM demagnetization curves, and magnetic hysteresis loops. High-temperature $\kappa-\mathrm{T}$ curves (room temperature to $700{ }^{\circ} \mathrm{C}$, then back to room temperature) were obtained using an AGICO KLY-3 Kappabridge with a CS-3 high-temperature furnace. IRM demagnetization curves and magnetic hysteresis loops were measured using a Princeton Measurements MicroMag Corporation 2900 alternating gradient magnetometer with a maximum field of $500 \mathrm{mT}$. All the magnetic measurements in this study were carried out at the Department of Geosciences, Tübingen University, Germany.

\section{Results}

4.1. Age-depth model and stratigraphic variations of sediment properties of Lugu Lake

Radiometric ${ }^{210} \mathrm{~Pb}$ and ${ }^{137} \mathrm{Cs}$ dates of core LGS-7 and six AMS ${ }^{14} \mathrm{C}$ dates of core LGS-2 have been reported by Wang et al. (2020). The age-depth model was ultimately developed using a combination of the ${ }^{137} \mathrm{Cs}$ date of $1963 \mathrm{CE}$ and six AMS ${ }^{14} \mathrm{C}$ dates by fitting the smooth-spline model with the Clam 2.2 software. This model covered the past 2800 years with a mean sedimentation rate of $2.5 \mathrm{~cm} / 100$ years and a rapid increase of the sedimentation rate during the past 200 years.

\subsubsection{Unit 1 (73-61.5 cm, 0-400 CE)}

This unit showed a significant decrease in pelagic cladocerans (Bosmina coregoni), coeval with a decline in abundance of planktimic taxa (C. dubiu) and an increase in Bosmina longispina. (Wang et al., 2020). The mean grain size before $400 \mathrm{CE}$ was moderately high, and Al and Ti contents showed low levels with means of $47 \mathrm{mg} / \mathrm{g}$ and $8 \mathrm{mg} / \mathrm{g}$, respectively, before $400 \mathrm{CE}$ (Wang et al., 2020) (Fig. 3). Magnetic susceptibility $(\chi)$ and saturation isothermal remanent magnetization (SIRM) can be used to reflect the changes of magnetic minerals concentrations, especially ferrimagnetic minerals like magnetite. The mean values of $\chi$ and SIRM were $33.39 \times 10^{-8} \mathrm{~m}^{3} / \mathrm{kg}$ and $2705.48 \times 10^{-6}$ $\mathrm{Am}^{2} / \mathrm{kg}$, respectively. $\chi_{\mathrm{fd}} \%$ can be used to show the contribution of superparamagnetic minerals. The mean value of $\chi_{\mathrm{fd}} \%$ was approximately $10.53 \%$, indicating the presence of superparamagnetic (SP) grains at room temperature. Hard isothermal remanent magnetization

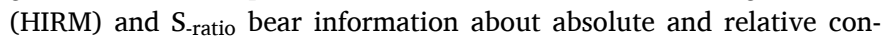
centrations of high coercivity minerals. The mean $S_{\text {-ratio }}$ and HIRM values were approximately 0.96 and $55.40 \times 10^{-6} \mathrm{Am}^{2} / \mathrm{kg}$, respectively, indicating that dominant remanence contributions are mainly from soft magnetic minerals (e.g., magnetite and maghemite) (Fig. 2, Table 1).

\subsubsection{Unit 2 (47.5-61.5 cm, 400-800 CE)}

This unit was characterized by a significant increase in the species of planktonic diatoms (especially C. dubius). In this unit, the biomass of primary producers was at the lowest level, indicated by stable pigment indicators of lower plant abundance and total algae. Lutein and zeaxanthin contents decreased significantly in this unit, indicating a decrease in production (Wang et al., 2020). The mean grain size was low but variable in this unit. Significant increases in $\mathrm{Al}$ and Ti were observed in this unit, corresponding to minimum values of total organic carbon (TOC), the carbon accumulation rate (CAR) and a low sand fraction (Wang et al., 2020) (Fig. 3). The $\chi$ and SIRM values were lower in this unit than in Unit 1 , showing a decrease of magnetic mineral concentration. Compared with Unit 1 , the $\mathrm{S}_{\text {-ratio }}$ (mean of 0.94 ) and $\chi_{\mathrm{fd}} \%$ (mean of $8.11 \%$ ) were lower, indicating a decrease of soft and SP magnetic mineral contents, which was also confirmed by the increase of HIRM. $\chi_{\mathrm{ARM}} / \chi$ and $\chi_{\mathrm{ARM}} / \mathrm{SIRM}$ have been used to trace relative changes in the grain size of magnetic minerals. The $\chi_{\mathrm{ARM}} / \chi$ values were higher than those of Unit 1, indicating that magnetic grain sizes were finer than 


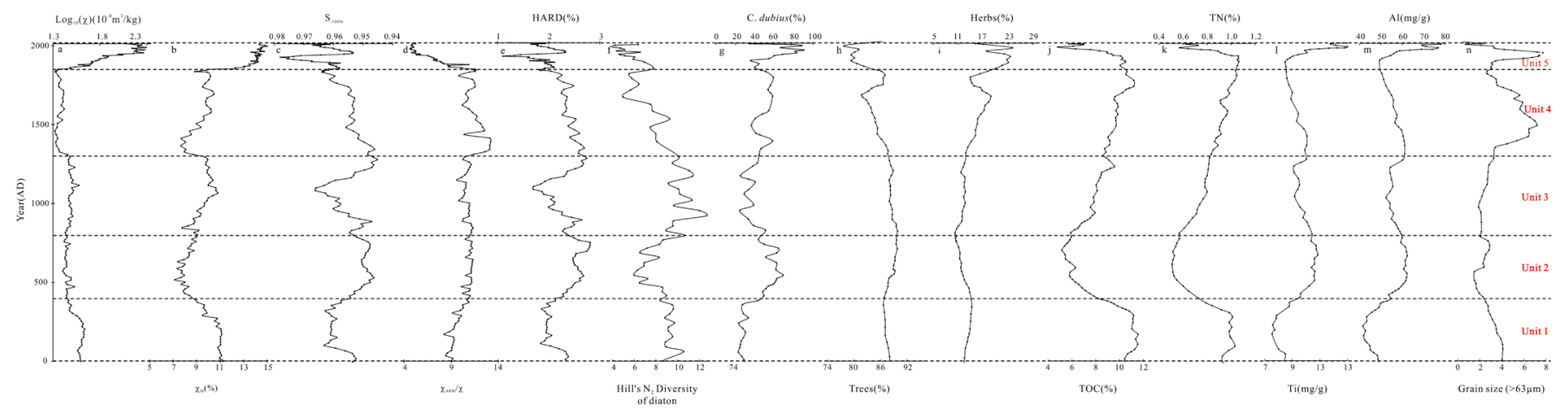

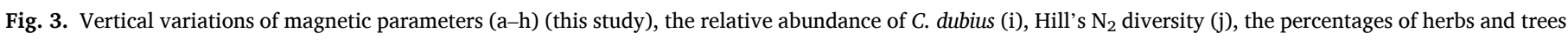
$(\mathrm{k}-1), \mathrm{TN}(\mathrm{m}), \mathrm{TN}(\mathrm{n}), \mathrm{Al}(\mathrm{o})$, and Ti (p) contents (Wang et al., 2020) in Lugu Lake sediments.

those in Unit 1 (Fig. 2, Table 1).

\subsubsection{Unit 3 (31.5-47.5 cm, $800-1300 \mathrm{CE})$}

This unit was marked by an increase in the abundance of small Fragilariaceae species and a decrease in the abundance of the planktonic species $C$. dubius. The Hill's $\mathrm{N}_{2}$ diversity and diatom accumulation rate (AR) started to decline in this unit. The concentrations of $\mathrm{Al}$ and $\mathrm{Ti}$ gradually decreased during the period of $1000-1300 \mathrm{CE}$, and the mean grain size and sand fraction then decreased significantly during the MWP (1000-1300 CE) (Wang et al., 2020) (Fig. 3). Compared with Unit 2 , the increased $\chi$ values (mean of $27.25 \times 10^{-8} \mathrm{~m}^{3} / \mathrm{kg}$ ) and SIRM values (mean of $2703.90 \times 10^{-6} \mathrm{Am}^{2} / \mathrm{kg}$ ) indicated the increase of magnetic mineral contents. HARD\% is proportional to the concentration of antiferromagnetic materials. The $\mathrm{S}_{\text {-ratio }}$, HIRM, and HARD values suggest that soft magnetic minerals dominated the magnetic components. The $\chi_{\mathrm{ARM}} / \chi$ and $\chi_{\mathrm{ARM}} / \mathrm{SIRM}$ values were lower than those in Unit 2 , indicating that the magnetic grain sizes became coarser (Fig. 2, Table 1).

\subsubsection{Unit $4(18-31.5 \mathrm{~cm}, 1300-1850 \mathrm{CE})$}

This unit is characterized by a clear increase of the relative abundance of small benthic Fragilariaceae species and a sudden disappearance of planktonic $C$. rhomboideo-elliptica. The sand fraction and mean grain size rose markedly during the period of $1300-1850 \mathrm{CE}$, which also corresponded to an abrupt increase in the abundance of cyanobacteria, as well as the disappearance of $C$. rhomboideo-elliptica and sedimentdwelling Leydigia sp. During the period of 1300-1850 CE, the abundance of the planktonic taxon C. rhomboideo-elliptica decreased significantly, and the content of pigments from diatoms increased markedly (Wang et al., 2020) (Fig. 3). The $\chi$ and SIRM values in this unit were the lowest of the entire core. In unit 4 , the values of $\chi_{\text {ARM }} / \chi$ and $\chi_{\text {ARM }} / S I R M$ were highest, indicating that the grain sizes of magnetic minerals were the finest in the entire core. The $\chi_{\mathrm{fd}} \%$ values decreased, indicating a decrease in SP magnetic mineral contents. The $\mathrm{S}_{\text {-ratio }}$ values were lower, and the HIRM and HARD values were higher. These findings show that the contents of soft magnetic components were lower (Fig. 2, Table 1).

\subsubsection{Unit 5 (0-18 cm, 1850-2012 CE)}

Based on the diatom records, this unit was subdivided into two subunits deposited in 1850-1950 CE and 1950-2012 CE. There was a sharp increase in small-sized Fragilariaceae species, particularly Pseudostaurosira brevistriata, during 1850-1950 CE. The contents of both the sand and fine silt/clay fractions increased considerably during 1850-1950 CE, whereas both remained low after $1950 \mathrm{CE}$. The $\mathrm{Al}$ and $\mathrm{Ti}$ values rose to their highest levels after $1950 \mathrm{CE}$, corresponding to the rapid declines of TOC and total nitrogen (TN) contents (Wang et al., 2020) (Fig. 3). Division of the two subunits was also supported by magnetic parameters. The $\chi$ and SIRM values showed that the contents of magnetic minerals in the 1950-2012 CE subunit were higher than those in the $1850-1950 \mathrm{CE}$ subunit. The $\chi_{\mathrm{ARM}} / \chi$ values of the
1950-2012 CE subunit were lower than those of the 1850-1950 CE subunit, indicating that the magnetic grain sizes deposited during 1950-2012 CE were coarser than those deposited during 1850-1950 CE (Fig. 2, Table 1).

\subsection{Magnetic hysteresis loop curves, $\kappa-T$ curves, demagnetization and IRM acquisitions curves}

Magnetic hysteresis loops can contain a large amount of information whether the coercivity of the magnetic mineralogy is high or low (Thompson and Oldfeld, 1986). The magnetic hysteresis loops of all the samples (samples: 9, 24, 52, 100, 148, and 192) showed that the loops could be saturated under $300 \mathrm{mT}$, suggesting that soft magnetic minerals were the dominant magnetic minerals. In addition, all the loops showed an increase from 300 to $1000 \mathrm{mT}$, indicating the presence of hard magnetic or paramagnetic minerals (Fig. $4 a-f$ ). In addition, the demagnetization curves of all the samples showed that the remanent magnetization could be easily demagnetized under $30-40 \mathrm{mT}$, which shows that soft magnetic minerals were dominant in all the samples (Fig. 4p). Similarly, the IRM acquisition curves of all samples indicate that IRM at $300 \mathrm{mT}$ is generally $>90 \%$ of the SIRM, which also reveals that soft magnetic minerals are predominant in these sample and the hard magnetic mineral contribution is low (Fig. 4q).

High-temperature $\kappa-T$ curves can be used to identify magnetic phases according to different magnetic minerals with different Curie temperatures (Tc). All the heating curves of the representative samples are shown in Fig. 4h-n. The heating curves show that magnetic susceptibility clearly increased at approximately $220{ }^{\circ} \mathrm{C}$, indicating the unblocking temperature of finer grain sizes near the boundaries of SP and SD ferrimagnetic particles (Liu and Deng, 2009; Ge et al., 2015), and then decreased significantly near $300-400{ }^{\circ} \mathrm{C}$ because thermally unstable maghemite transformed into hematite during heating (Hao and Guo, 2005; Chen et al., 2005; Ma et al., 2020). Above $400^{\circ} \mathrm{C}$, a peak of all the heating curves occurred with a temperature of approximately $500{ }^{\circ} \mathrm{C}$, which may be related to the transformation of paramagnetic minerals into ferrimagnetic minerals (Pan et al., 2000; Ge et al., 2015). There were clear Tc values of approximately $580{ }^{\circ} \mathrm{C}$, indicating that the dominant magnetic minerals were magnetite. All the heating curves have transition position at near $675^{\circ} \mathrm{C}$, representing the Neel temperature of hematite (Dunlop and Ozdemir, 1997). In addition, the magnetic susceptibilities of all the cooling curves were higher than those of the heating curves, which also indicated the formation of ferrimagnetic minerals during heating (Fig. $4 \mathrm{~h}-\mathrm{n}$ ).

We further applied a log-Gaussian decomposition of IRM acquisition curves proposed by Kruiver et al. (2001). Two components with distinct magnetic coercivities can be separated in Fig. 5 . Component 1 with $B_{1 / 2}$ values (the coercivity field at half of the SIRM) of $41.7-49 \mathrm{mT}$, a mean value of $45.57 \mathrm{mT}$, DP (dispersion parameter) of $0.51-0.67$, and $\mathrm{M}_{\mathrm{ri}}$ (remanence contribution) of 95-98\%. Component 2 with $\mathrm{B}_{1 / 2}$ values of 

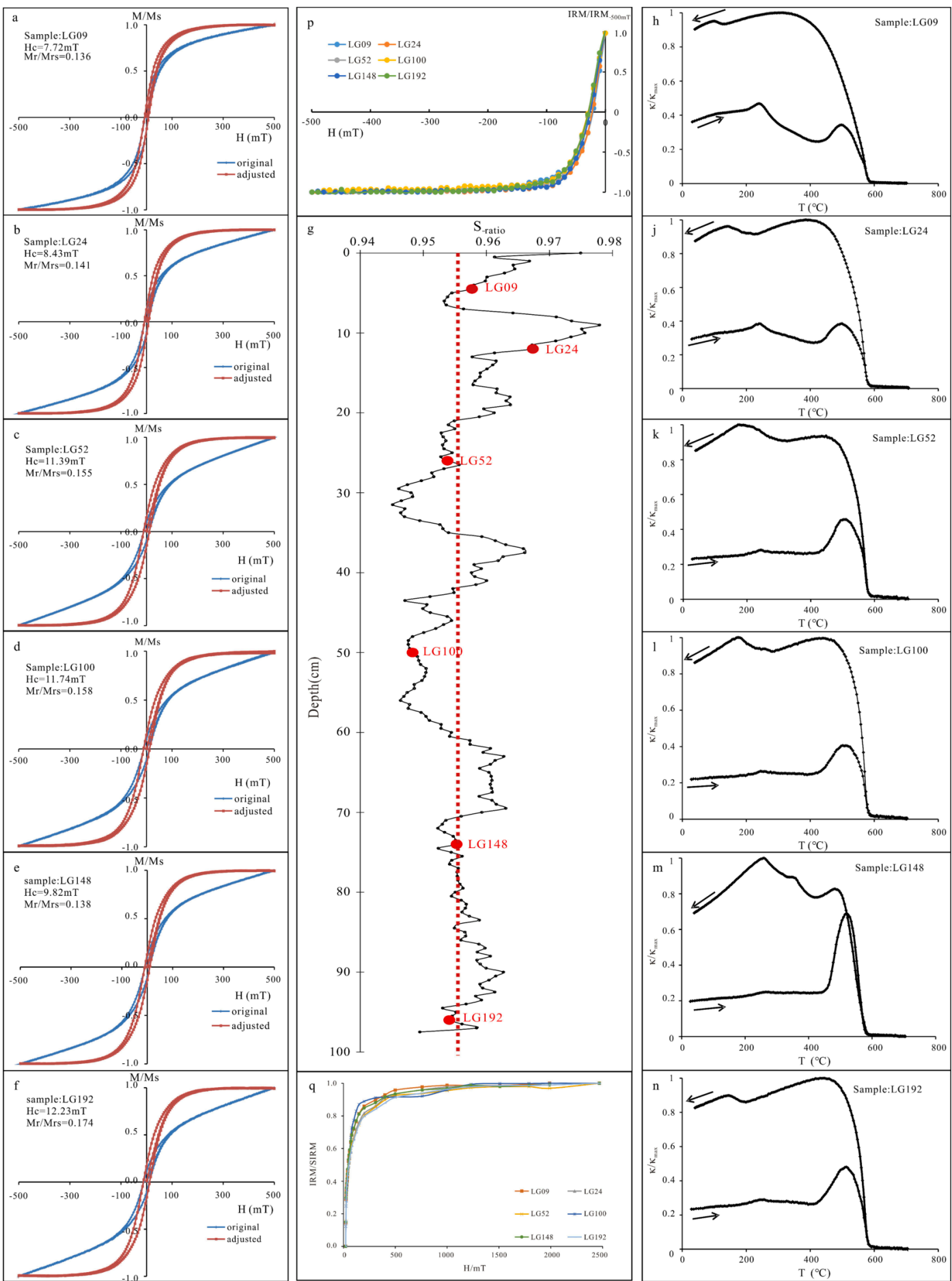

Fig. 4. The depths of representative samples shown in the $\mathrm{S}_{\text {-ratio }}$ curve ( $\mathrm{g}$ ). Magnetic hysteresis (a-f), high-temperature $\mathrm{k}-\mathrm{T}$ curves (i-n), demagnetization curves (p) and IRM acquisition curves (q) of a representative sample from Lugu Lake.

631-794.3 mT, a mean value of 738.2 mT, DP of $0.60-1.00$, and $\mathrm{M}_{\mathrm{ri}}$ of 2-5\%. The SIRM values of representative samples are between 2101.62 and $7973.39 \times 10^{-6} \mathrm{Am}^{2} / \mathrm{kg}$ (Table 3). Combined with the results of the heating curves, we concluded that component 1 can be interpreted as magnetite and maghemite, and the high-coercivity component 2 may represent hard magnetic minerals.

\section{Discussion}

\subsection{Sources and characteristics of magnetic minerals}

The primary principle that needs to be clarified when magnetic parameters are used to reconstruct paleoenvironmental change is the origin of the magnetic minerals in the sediments. At a large scale, there are two magnetic minerals types in the lake sediments: anthropogenic and natural. Previous studies showed that correlations between $\chi$ and both $\chi_{\mathrm{fd}} \%$ and $\chi_{\mathrm{ARM}} / \chi$ can be used to identify anthropogenic magnetic 
$\operatorname{Lg} 09$
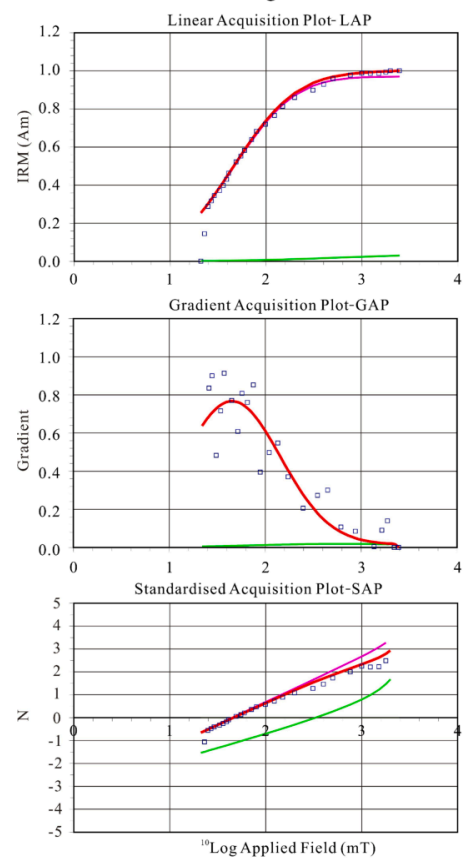

LG 100
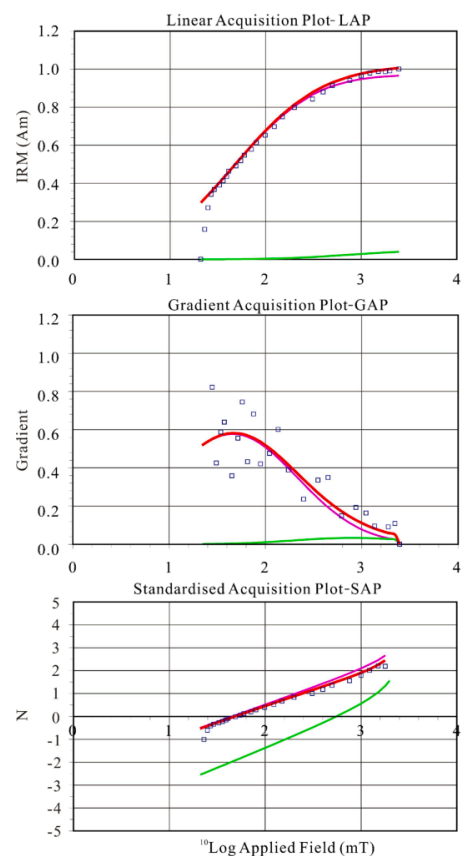

LG24
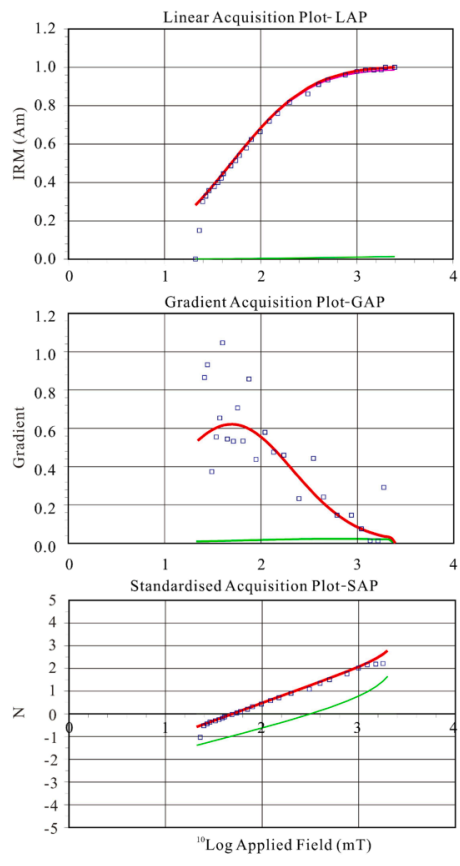

LG148
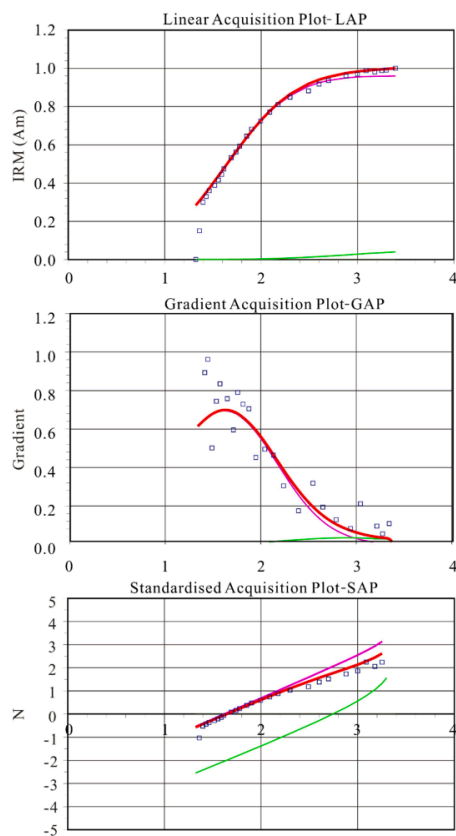

${ }^{10}$ Log Applied Field $(\mathrm{mT})$
LG52
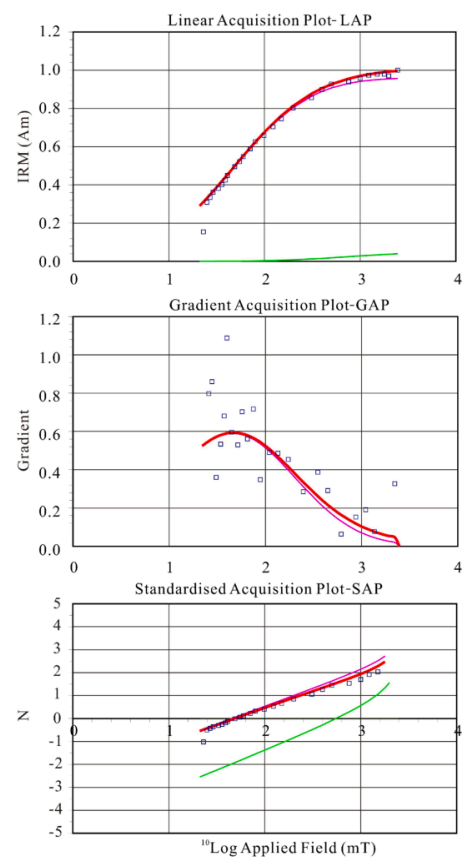

LG192
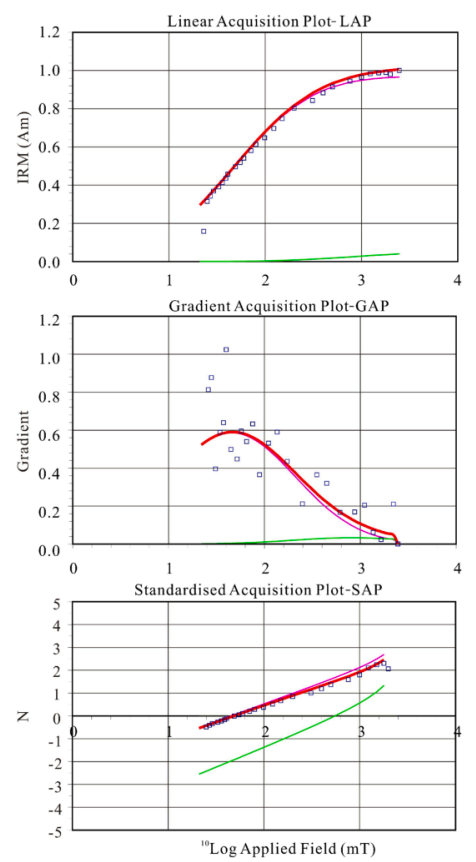

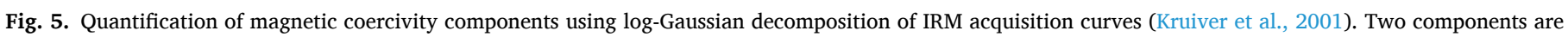
separated: component 1 represents soft magnetic minerals (magnetite), while component 2 represents hard magnetic minerals (hematite).
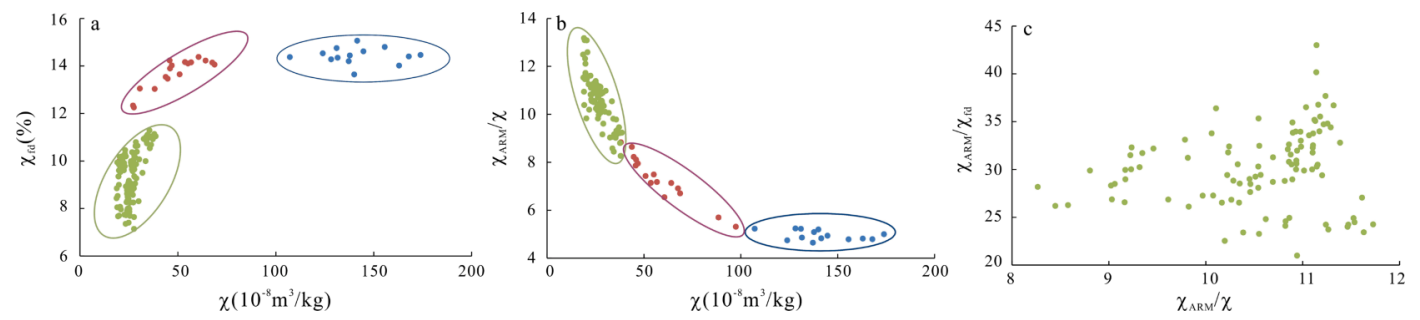

Fig. 6. Scatterplots of (a) $\chi$ vs. $\chi_{\mathrm{fd}} \%$, (b) $\chi$ vs. $\chi_{\mathrm{ARM}} / \mathrm{SIRM}$, and (c) $\chi_{\mathrm{ARM}} / \chi_{\mathrm{fd}} \%$ vs. $\chi_{\mathrm{ARM}} / \chi$ for the samples from Lugu Lake. The blue, red, and green circles represent samples from depths of 0 to $7 \mathrm{~cm}$ (1950-2012 CE), 7 to $18 \mathrm{~cm}$ (1850-1950 CE), and 18 to $73 \mathrm{~cm}(0-1850 \mathrm{CE})$, respectively. (For interpretation of the references to colour in this figure legend, the reader is referred to the web version of this article.) 
Table 2

Pearson correlation coefficients of magnetic parameters and other environmental proxies.

\begin{tabular}{|c|c|c|c|c|c|c|c|c|c|c|c|c|c|c|c|c|}
\hline Age & & $\chi$ & $\chi_{\text {ARM }}$ & SIRM & $\mathrm{S}_{\text {-ratio }}$ & $\chi_{\mathrm{ARM}} / \chi$ & $\chi_{\text {ARM }} / \mathrm{SIRM}$ & HIRM & SIRM $/ \chi$ & Trees & Herbs & TOC & $\mathrm{TN}$ & $\mathrm{Ti}$ & $\mathrm{Al}$ & Grain size \\
\hline \multirow[t]{14}{*}{$0-1850 \mathrm{CE}$} & $\chi$ & 1 & 0.941 & 0.824 & 0.253 & -0.866 & 0.350 & 0.224 & -0.851 & 0.293 & -0.365 & 0.028 & -0.443 & 0.712 & 0.673 & -0.132 \\
\hline & $\chi_{\text {ARM }}$ & & 1 & 0.873 & 0.217 & -0.660 & 0.383 & 0.263 & -0.702 & 0.282 & -0.327 & -0.053 & -0.338 & 0.693 & 0.542 & -0.021 \\
\hline & SIRM & & & 1 & 0.125 & -0.629 & -0.112 & 0.425 & -0.416 & 0.215 & -0.272 & -0.269 & -0.411 & 0.744 & 0.673 & 0.003 \\
\hline & $S$ ratio & & & & 1 & -0.170 & 0.201 & -0.753 & -0.235 & 0.060 & -0.150 & 0.043 & -0.391 & -0.169 & 0.146 & -0.174 \\
\hline & $\chi_{\mathrm{ARM}} / \chi$ & & & & & 1 & -0.134 & -0.128 & 0.853 & -0.118 & 0.187 & -0.017 & 0.346 & -0.321 & -0.533 & 0.225 \\
\hline & $\chi_{\mathrm{ARM}} / \mathrm{SIRM}$ & & & & & & 1 & -0.262 & -0.636 & -0.022 & 0.064 & 0.494 & 0.340 & -0.556 & -0.635 & -0.067 \\
\hline & HIRM & & & & & & & 1 & 0.051 & 0.025 & 0.009 & -0.214 & 0.076 & 0.536 & 0.243 & 0.181 \\
\hline & SIRM $/ \chi$ & & & & & & & & 1 & -0.129 & 0.155 & -0.422 & -0.032 & 0.353 & 0.214 & 0.374 \\
\hline & Trees & & & & & & & & & 1 & -0.541 & 0.132 & -0.223 & 0.493 & -0.024 & -0.418 \\
\hline & Herbs & & & & & & & & & & 1 & -0.129 & 0.261 & -0.507 & -0.029 & 0.356 \\
\hline & тоС & & & & & & & & & & & 1 & 0.621 & -0.024 & -0.773 & -0.144 \\
\hline & $\mathrm{TN}$ & & & & & & & & & & & & 1 & -0.184 & -0.701 & 0.188 \\
\hline & $\mathrm{Ti}$ & & & & & & & & & & & & & 1 & 0.359 & -0.186 \\
\hline & $\mathrm{Al}$ & & & & & & & & & & & & & & 1 & 0.064 \\
\hline \multirow{15}{*}{$1850-2012 \mathrm{CE}$} & grain size & 1 & 0990 & & & & & & & 0298 & & 0.643 & 0156 & & 0336 & 1 \\
\hline & $\chi_{\gamma}^{\chi}$ & & $\begin{array}{l}0.990 \\
1\end{array}$ & $\begin{array}{l}0.980 \\
0.974\end{array}$ & $\begin{array}{l}-0.229 \\
-0.219\end{array}$ & $\begin{array}{l}-0.901 \\
-0.879\end{array}$ & $\begin{array}{l}-0.724 \\
-0.724\end{array}$ & $\begin{array}{l}0.855 \\
0.854\end{array}$ & $\begin{array}{l}-0.795 \\
-0.789\end{array}$ & $\begin{array}{l}-0.298 \\
-0.240\end{array}$ & $\begin{array}{l}0.133 \\
0.135\end{array}$ & $\begin{array}{l}0.043 \\
0.569\end{array}$ & -0.274 & $\begin{array}{l}-0.375 \\
-0.268\end{array}$ & $\begin{array}{l}0.030 \\
0.355\end{array}$ & $\begin{array}{l}0.557 \\
0.529\end{array}$ \\
\hline & SIRM & & & 1 & -0.229 & -0.866 & -0.854 & 0.865 & -0.704 & -0.324 & -0.057 & 0.656 & 0.061 & -0.419 & 0.079 & 0.484 \\
\hline & $S$ ratio & & & & 1 & 0.052 & 0.227 & -0.609 & -0.013 & -0.007 & 0.203 & -0.004 & 0.760 & -0.491 & -0.779 & -0.491 \\
\hline & $\chi_{\mathrm{ARM}} / \chi$ & & & & & 1 & 0.705 & -0.696 & 0.936 & 0.290 & -0.083 & -0.656 & -0.310 & 0.569 & -0.013 & -0.480 \\
\hline & $\chi_{\text {ARM }} /$ SIRM & & & & & & 1 & -0.727 & 0.416 & 0.080 & 0.316 & -0.577 & -0.494 & 0.530 & 0.398 & -0.273 \\
\hline & HIRM & & & & & & & 1 & -0.561 & -0.158 & -0.200 & 0.308 & -0.575 & 0.108 & 0.635 & 0.594 \\
\hline & $\operatorname{SIRM} / \chi$ & & & & & & & & 1 & 0.061 & -0.274 & -0.061 & 0.335 & -0.113 & -0.391 & -0.385 \\
\hline & Trees & & & & & & & & & 1 & -0.876 & -0.388 & -0.517 & 0.598 & 0.472 & 0.384 \\
\hline & Herbs & & & & & & & & & & 1 & 0.352 & 0.447 & -0.487 & -0.434 & -0.620 \\
\hline & TOC & & & & & & & & & & & 1 & 0.740 & -0.853 & -0.852 & 0.238 \\
\hline & $\mathrm{TN}$ & & & & & & & & & & & & 1 & -0.877 & -0.940 & -0.521 \\
\hline & $\mathrm{Ti}$ & & & & & & & & & & & & & 1 & 0.867 & 0.051 \\
\hline & $\mathrm{Al}$ & & & & & & & & & & & & & & 1 & 0.745 \\
\hline & grain size & & & & & & & & & & & & & & & 1 \\
\hline
\end{tabular}


Table 3

Coercivity component parameters of the representative samples from Lugu Lake (SIRM: saturation isothermal remanent magnetization, $\mathrm{B}_{1 / 2}$ : the coercivity field at half of the SIRM, DP: dispersion parameter, $\mathrm{M}_{\mathrm{ri}}$ : romance contribution).

\begin{tabular}{lllllll}
\hline Sample & $\begin{array}{l}\text { SIRM } \\
\left(10^{-6} \mathrm{Am}^{2} / \mathrm{kg}\right)\end{array}$ & Components & $\begin{array}{l}\log \left(\mathrm{B}_{1 /}\right. \\
2)(\mathrm{mT})\end{array}$ & $\begin{array}{l}\mathrm{B}_{1 / 2} \\
(\mathrm{mT})\end{array}$ & DP & $\begin{array}{l}\mathrm{M}_{\mathrm{ri}} \\
(\%)\end{array}$ \\
\hline LG09 & \multirow{2}{*}{ 2973.36 } & 1 & 1.65 & 44.9 & 0.51 & 96 \\
& & 2 & 2.80 & 631 & 0.88 & 4 \\
LG24 & \multirow{2}{*}{3124.64} & 1 & 1.69 & 49 & 0.64 & 98 \\
& & 2 & 2.86 & 695 & 1.00 & 2 \\
LG52 & \multirow{2}{*}{2101.62} & 1 & 1.68 & 45.3 & 0.65 & 95 \\
& & 2 & 2.93 & 732 & 0.67 & 5 \\
LG100 & \multirow{2}{*}{2831.97} & 1 & 1.67 & 46.8 & 0.67 & 96 \\
& & 2 & 2.89 & 785.2 & 0.62 & 4 \\
LG148 & \multirow{2}{*}{2829.69} & 1 & 1.62 & 41.7 & 0.55 & 97 \\
& & 2 & 2.87 & 791.7 & 0.66 & 3 \\
LG192 & \multirow{2}{*}{2369.74} & 1 & 1.64 & 45.7 & 0.66 & 95 \\
& & 2 & 2.91 & 794.3 & 0.60 & 5 \\
\hline
\end{tabular}

minerals (Ma et al., 2014; Wang et al., 2018a, 2018b). Based on the relationships of $\chi$ vs. $\chi_{\mathrm{fd}} \%$ and $\chi$ vs. $\chi_{\mathrm{ARM}} / \chi$, the samples can be divided into three parts. The samples deposited between 1950 and $2012 \mathrm{CE}$ were influenced by heavy metal pollution, which was caused by modern industrial activities (Lin et al., 2018; Wang et al., 2018a, 2018b). Although the values of TOC (total organic carbon) and TN (total nitrogen) are lower between 1950 and $2012 \mathrm{CE}$, showing the increase in human activities decrease significantly. The previous studies have shown that the causes of heavy metal pollution were mainly from atmospheric metal deposition from anthropogenic sources (Lin et al., 2018; Wang et al., 2018a, 2018b). We estimated that increase of magnetic mineral contents between 1950 and $2012 \mathrm{CE}$ was caused by the atmospheric metal deposition rather than the local mining wastewater (Fig. 4). As also shown by TOC and TN values, intensified agriculture and catchment erosion caused by population expansion affected the samples deposited between 1850 and $1950 \mathrm{CE}$ (Fig. 7h). The $\chi$ values of the samples deposited from 0 to $1850 \mathrm{CE}$ were low, which indicated that natural sources were the main sources of magnetic minerals (Fig. 7a).

The magnetic minerals derived from natural sources, between 0 and $1850 \mathrm{CE}$, may be of biogenic and detrital origins" with references intact (Liu et al., 2012; Wang et al., 2018a, 2018b). Magnetic mineral types must be confirmed before the natural sources of magnetic minerals are determined. First, $\mathrm{S}_{\text {-ratios }}$ can indicate the relative proportions of hard

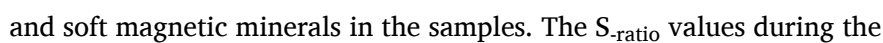
period of $0-1300 \mathrm{CE}$ ranged from 0.94 to 0.98 with a mean of 0.96 , which indicates that soft magnetic minerals dominated the magnetic signal of these sediments. Secondly, the magnetic hysteresis loop curves, $\kappa-T$ curves, log-Gaussian decomposition of IRM acquisition curves and demagnetization curves demonstrate that magnetite dominated the magnetic mineral assemblage. Additionally, different magnetic minerals have different SIRM $/ \chi$ values, such as $11 \times 10^{3} \mathrm{~A} / \mathrm{m}$ for magnetite, 209 $\times 10^{3} \mathrm{~A} / \mathrm{m}$ for pyrrhotite, and $261 \times 10^{3} \mathrm{~A} / \mathrm{m}$ for hematite (Maher, 2007; Wang et al., 2018a, 2018b). The SIRM/ $\chi$ values of the sediments from Lugu Lake deposited during $0-1850 \mathrm{CE}$ ranged from 6.52 to 11.10 $\times 10^{3} \mathrm{~A} / \mathrm{m}$, with a mean of $8.92 \times 10^{3} \mathrm{~A} / \mathrm{m}$. The SIRM $/ \chi$ values are similar to the values of magnetite, whose presence was also supported by the log-Gaussian decomposition of IRM acquisition curves. According to the bi-logarithmic plot of $\chi_{\mathrm{ARM}} / \chi$ vs. $\chi_{\mathrm{ARM}} / \chi_{\mathrm{fd}} \%$ in the lake sediments by Oldfield (1994), high $\chi_{\mathrm{ARM}} / \chi_{\mathrm{fd}} \%$ and $\chi_{\mathrm{ARM}} / \chi$ values, especially when $\chi_{\mathrm{ARM}} / \chi_{\mathrm{fd}} \%$ values are greater than $1.0 \times 10^{3}$, indicate that the magnetite is biogenic in origin. As shown in Fig. $6 \mathrm{c}$, the values of $\chi_{\mathrm{ARM}} / \chi$ ranged from 7.98 to 13.18 , with a mean of 10.28 , and $\chi_{\mathrm{ARM}} / \chi_{\mathrm{fd}} \%$ ranged from 19.61 to 43.02 , with a mean of 29.61 (Fig. 5c). Both ranges are low, which indicates that the magnetic minerals of Lugu Lake sediments can primarily be attributed to detrital rather than biogenic sources.

However, many studies showed that magnetic minerals will be transformed or dissolved under excessive humid or water-logged conditions, represented by the dissolution of iron oxide (such as magnetite and maghemite) and the formation of iron hydroxide (such as goethite) and sulfides (such as greigite) (Roberts, 2015; Xu et al., 2020). The high $\kappa-\mathrm{T}$ curves indicate that magnetite and maghemite are the main magnetic carriers, and there are no signs for iron hydroxide or sulfides. In addition, previous studies have shown that the dissolution effects on magnetic minerals are modulated by the availability and reactivity by organic matter. When the contents of organic matter of sediments were high, both concentrations and grain size of magnetic minerals decreased (Snowball, 1993; Nowaczyk et al., 2001; Ao et al., 2010; Roberts, 2015; Wang et al., 2015). The positive relationship between $\chi$ and TOC and the negative relationship between $\chi_{\mathrm{ARM}} / \chi$ and TOC suggested that the dissolution effects for magnetic minerals are negligible (Table 2). All these indicated that dissolution effects for magnetic minerals were negligible. A significantly positive correlation exists between $\chi$ and SIRM (Table 2), which demonstrates a predominant contribution of ferrimagnetic minerals. Such a linear relationship between $\chi$ and SIRM

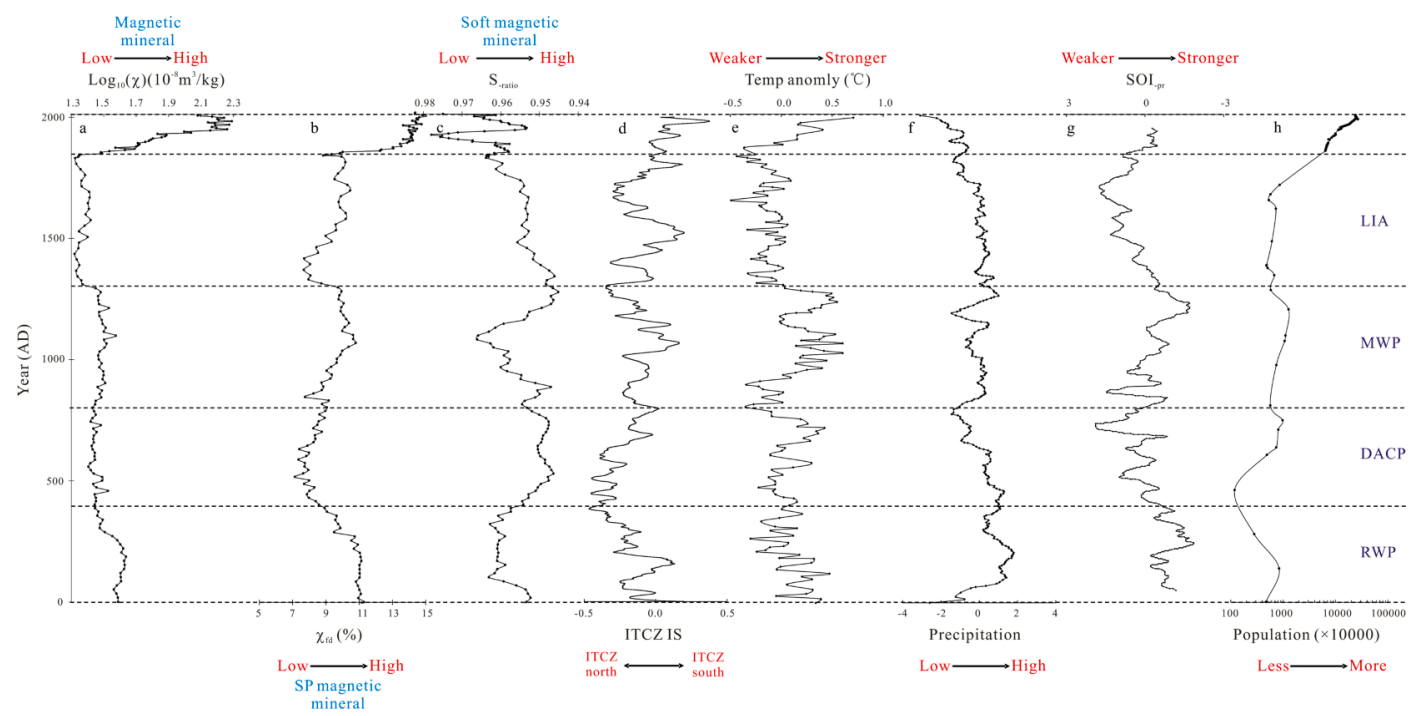

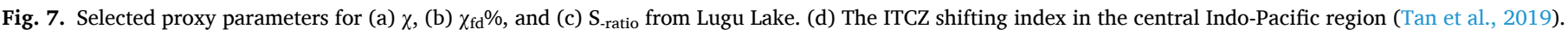

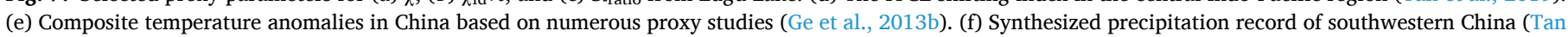

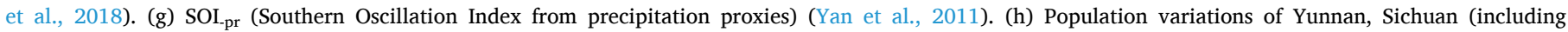
Chongqing), Guangxi, Xizang, and Guizhou provinces during the past 2000 years (Zhao and Xie, 1988). 
also reveals that changes in magnetization mainly reflect changes in the concentration rather than the grain size of magnetic particles.

\subsection{Climatic variability derived from magnetic records and possible driving forces}

Lugu Lake is a seasonal and closed alpine lake. The rivers flowing into Lugu Lake are quite short. Thus, magnetic minerals of the sediments mainly originate from the soil and weathered rock debris in the basin (Wang and Dou, 1998; Zhang et al., 2013). Compared with shallow lakes, the influences of water-level fluctuation on the sediments of Lugu Lake are negligible. Surface runoff intensity, erosion patterns, and provenance are the main factors affecting the magnetic minerals of sediments. The content and type of magnetic minerals in sediments are controlled by the weathering intensity. Generally, the weathering intensity is stronger in the warm and humid environment, which is more conducive to the formation and enrichment of magnetic minerals (Liu et al., 2021). Thus, we speculated that because of strong weathering and pedogenesis in tropical and subtropical areas of China, the ferromagnetic mineral contents of the surface sediments are high, and the grain size is coarse (Huang, 1996). When the chemical weathering of deep soil is relatively weak, the contents of antiferromagnetic minerals are higher. The $\chi$ values of deep soil are low, and the grain size are finer (Wang et al., 2011). Generally, when the amount of precipitation is small, the main erosion type is surface erosion (He et al., 2005). Conversely, when precipitation is strong, the main erosion types are mainly rill erosion, gully erosion, and bank erosion (He et al., 2005). Thus, most sediments carried by flowing water come from deeper soil. Precipitation variation determines the composition of terrestrial debris entering Lugu Lake by influencing the surface runoff intensity. Changes of catchment erosion types caused by changes in precipitation may have resulted in changes of the magnetic minerals, which also supported by the changes of grain size $(>63 \mu \mathrm{m})$. A previous study that reported $\chi$ values of 22 surface sediments and rock samples in the basin of Lugu Lake indicated that the average $\chi$ values of surface and rock samples were $575 \times 10^{-8} \mathrm{~m}^{3} / \mathrm{kg}$ and $41 \times 10^{-8} \mathrm{~m}^{3} / \mathrm{kg}$, respectively (Lin et al., 2017). As a result, $\chi, \chi_{\mathrm{fd}} \%$, and $\mathrm{S}_{\text {-ratio }}$ can be used as sensitive indicators of paleoenvironmental change.

The values of $\chi, \chi_{\mathrm{fd}} \%$, and $\mathrm{S}_{\text {-ratio }}$ during $0-1850 \mathrm{CE}$ can be divided into two periods with high values and two periods with low values (Fig. 7a-c). The two high-value periods lasted from 0 to $400 \mathrm{CE}$ and from 800 to $1300 \mathrm{CE}$, which correspond to the RWP and MWP, respectively. The two low-value periods lasted from 400 to $800 \mathrm{CE}$ and from 1300 to $1850 \mathrm{CE}$, which correspond to the DACP and LIA, respectively. Evidently, the main climatic fluctuations of the past 2000 years in the Northern Hemisphere have been documented by the magnetic parameters of the sediments of Lugu Lake. Previous proxy studies suggested that conditions were wetter in southwestern China during the LIA than during the MWP (Fig. 7e, f), which is also supported by the magnetic parameters. In contrast to the magnetic characteristics of the LIA, the magnetic parameters also indicated wet conditions during the DACP in southwestern China. The main erosion types in the DACP were rill erosion, gully erosion, and bank erosion, and more hard magnetic minerals were caught and deposited in Lugu Lake in the DACP. Decreased abundance of tree pollen and increased herb pollen percentages during the MWP and RWP showed that the climatic conditions were dry, which was also supported by the Ti and Al contents (Wang et al., 2020). In these periods, the main erosion type was surface erosion. More surface sediments were transported into Lugu Lake, which resulted in the increase of SP and soft magnetic mineral contents.

The high-resolution magnetic record from Lugu Lake during 0-1850 $\mathrm{CE}$ provided us with an opportunity to examine the driving forces of paleoenvironmental change. A large number of studies have shown that many factors likely affect climatic variability in the southwest region of China, including El Niño/Southern Oscillation (ENSO) (Wang et al., 2000; Kumar et al., 2006), tropical Indo-Pacific sea surface temperature
(SST) (Li et al., 2001; Chu et al., 2014), and the Intertropical Convergence Zone (ITCZ) (An et al., 2015; Tan et al., 2019). However, what drives paleoenvironmental change in the southwest region of China still remains unclear. The shifts of the ITCZ together with ENSO are generally thought to be the two fundamental forcings that drive subtropical/ tropical environmental and climatic changes. It is generally believed that there is an inverse relationship between ENSO, the ITCZ, and precipitation on an annual to decadal timescale (Yan et al., 2011; Sheng et al., 2015; Tan et al., 2019; Xu et al., 2019). The southward displacement of the ITCZ during the MWP and RWP, as well as relative northward displacement during the LIA and DACP, could have led to changes of rainfall (with relatively drier conditions in the MWP and RWP but wetter conditions in the LIA and DACP). In addition, it is widely accepted that there exists an inverse relationship between ENSO and rainfall in annual to decadal times (with more ENSO conditions during the MWP and RWP, and less ENSO conditions during the LIA and DACP). The $\Delta^{18} \mathrm{O}$-based ITCZ shifting index (ITCZ IS) proposed by Tan et al. (2019) shows an overall southward movement trend over the past two millennia (Fig. 7d). The Southern Oscillation index from precipitation proxies (SOI-pr) by Yan et al. (2011) was proposed based on the strong and persistent correlation between the Southern Oscillation index and precipitation in the past 2000 years (Fig. $7 \mathrm{~g}$ ). Based on comparison between magnetic parameters and both the ITCZ IS and SOI-pr, the high contents of magnetic minerals (low precipitation) correspond to the southward of ITCZ and strong ENSO intensity, vice versa. We speculate that ENSO and the ITZC may have played important roles in influencing magnetic minerals during the last 2000 years. Therefore, it is likely that the combined effect of ENSO and ITCZ shifts could be responsible for the "wet/dry" hydroclimatic conditions over the tropical/subtropical Asian monsoon region.

\section{Conclusions}

High-resolution proxy records for the last 2000 years including magnetic parameters, diatoms, and geochemistry from Lugu Lake, northwestern Yunnan Province, were used to investigate ISM precipitation variability. Detailed magnetic measurements demonstrated that the dominant magnetic particles were magnetite. Natural sources and anthropogenic activities are considered to be the sources of the magnetic minerals based on the correlations of $\chi$ vs. $\chi_{\mathrm{fd}} \%$ and $\chi_{\mathrm{ARM}} / \chi$. The magnetic minerals of natural origins can be primarily attributed to detrital input rather than biogenic sources. Magnetic parameters including $\chi$, $\chi_{\mathrm{fd}} \%$, and $\mathrm{S}_{\text {-ratio }}$ can be used as sensitive indicators of ISM change, and suggest that two significant dry periods occurred in the MWP (800-1300 CE) and RWP (0-400 CE) and two relatively wet intervals in the DACP (400-800 CE) and LIA (1300-1850 CE). Significant shifts of magnetic parameters in Lugu Lake sediments revealed considerable sensitivity to precipitation-controlled catchment erosion, which then influenced the magnetic minerals. The rainfall caused by the ISM during the last 2000 years may have been influenced by variations of ENSO and the migration of the mean position of the ITCZ.

\section{Declaration of Competing Interest}

The authors declare that they have no known competing financial interests or personal relationships that could have appeared to influence the work reported in this paper.

\section{Acknowledgments}

This research was supported financially by the National Natural Science Foundation of China (No. U1706220, 41702185, 41572152, 31800421, 41977039), the Natural Science Foundation of Shandong Province (No. ZR2018PD005, ZR2018PC004), the Foundation of School and Land Integration Development in Yantai (2021XDRHXMQT18), Humanity and Social Science Foundation of Ministry of Education of 
China (NO. 19YJCZH171), the Open Foundation of State Key Laboratory of Loess and Quaternary Geology, Institute of Earth Environment, CAS (NO. SKLLQG2024), the Open Foundation of CAS Key Laboratory of Coastal Environmental Processes and Ecological Remediation, YICCAS (NO. 2020KGJJ10), the Key Research and Development Plan of Shandong Province (2019GSF107018), the Sino-German Center for Research Promotion (No. GZ675), the Chinese Academy of Sciences Visiting Professorship for Senior International Scientists (No. 2012T1Z0004). We thank Prof. Erwin Appel (University of Tübingen) for instructive comments and providing facilities for magnetic measurements.

\section{Appendix A. Supplementary data}

Supplementary data to this article can be found online at https://doi. org/10.1016/j.palaeo.2021.110581.

\section{References}

Agnihotri, R., Dutta, K., Bhushan, R., Somayajulu, B.L.K., 2002. Evidence for solar forcing on the Indian monsoon during the last millennium. Earth Planet. Sci. Lett. $198,521-527$.

An, Z., Porter, S.C., Kutzbach, J.E., Wu, X., Wang, S., Liu, X., Li, X., Zhou, W., 2000. Asynchronous holocene optimum of the east asian monsoon. Quat. Sci. Rev. 19, 743-762.

An, Z., Wu, G., Li, J., Sun, Y., Liu, Y., Zhou, W., Cai, Y., Duan, A., Li, L., Mao, J., Cheng, H., Shi, Z., Tan, L., Yan, H., Ao, H., Chang, H., Feng, J., 2015. Global monsoon dynamics and climate change. Annu. Rev. Earth Planet. Sci. 43, 1-49.

Anderson, D.M., Overpeck, J.T., Gupta, A.K., 2002. Increase in the Asian southwest monsoon during the past four centuries. Science 297, 596-599.

Ao, H., Deng, C.L., Dekkers, M.J., Liu, Q.S., 2010. Magnetic mineral dissolution in Pleistocene fluvio-lacustrine sediments, Nihewan Basin (North China). Earth Planet Sci. Lett. 292, 191-200.

Chang, L., Roberts, A.P., Heslop, D., Hayashida, A., Li, J.H., Zhao, X., Tian, W., Huang, Q. H., 2016. Widespread occurrence of silicate-hosted magnetic mineral inclusions in marine sediments and their contribution to paleomagnetic recording. J. Geophy. Res. 121, 8415-8431.

Chen, T., Xu, H., Xie, Q., Chen, J., Ji, J., Lu, H., 2005. Characteristics and genesis of maghemite in Chinese loess and paleosols: mechanism for magnetic susceptibility enhancement in paleosols. Earth Planet. Sci. Lett. 240 (3-4), 790-802.

Chen, C.H., Zhao, L.Y., Zhu, C., Wang, J.Z., Jiang, J.H., Yang, S., 2014. Response of diatom community in Lugu Lake (Yunnan-Guizhou Plateau, China) to climate change over the past century. J. Paleolimnol. 51, 357-373.

Chen, J., Chen, F., Feng, S., Huang, W., Liu, J., Zhou, A., 2015. Hydroclimatic changes in China and surroundings during the Medieval Climate Anomaly and Little Ice Age: spatial patterns and possible mechanisms. Quat. Sci. Rev. 107, 98-111.

Chen, H.F., Liu, Y.C., Chiang, C.W., Liu, X.Q., Chou, Y.M., Pan, H.J., 2019. China's historical record when searching for tropical cyclones corresponding to Intertropical Convergence Zone (ITCZ) shifts over the past 2 kyr. Clim. Past 15, 279-289.

Chu, G., Sun, Q., Xie, M., Lin, Y., Shang, W., Zhu, Q., Shan, Y., Xu, D., Rioual, P., Wang, L., Liu, J., 2014. Holocene cyclic climatic variations and the role of the Pacific Ocean as recorded in varved sediments from northeastern China. Quat. Sci. Rev. 102, 85-95.

Cook, E.R., Anchukaitis, K.J., Buckley, B.M., D’Arrigo, R.D., Jacoby, G.C., Wright, W.E., 2010. Asian monsoon failure and megadrought during the last millennium. Science 328, 486-489.

Cui, A.N., Ma, C.M., Zhao, L., Tang, L.Y., Jia, Y.L., 2018. Pollen records of the Little Ice Age humidity flip in the middle Yangtze River catchment. Quat. Sci. Rev. 193, 43-53.

Diaz, H.F., Trigo, R., Hughes, M.K., Mann, M.E., Xoplaki, E., Barriopedro, D., 2011. Spatial and temporal characteristics of climate in medieval times revisited. Bull. Am. Meteorol. Soc. 92, 1487-1500.

Dixit, Y., Tandon, S.K., 2016. Hydroclimatic variability on the Indian subcontinent in the past millennium: Review and assessment. Earth Sci. Rev. 161, 1-15.

Dixit, Y., Hodell, D.A., Petrie, C.A., 2014. Abrupt weakening of the summer monsoon in northwest India $\sim 4100$ yr ago. Geology 42, 339-342.

Dunlop, D., Ozdemir, O., 1997. Rock Magnetism: Fundamentals and Frontiers. Cambridge University Press.

Feng, X.P., Zhao, C., D'Andrea, W.J., Liang, J., Zhou, A.F., Shen, J., 2019. Temperature fluctuations during the Common Era in subtropical southwestern China inferred from brGDGTs in a remote alpine lake. Earth Planet. Sci. Lett. 510, 26-36.

Gao, X.B., Hao, Q.Z., Wang, L., Oldfield, F., Bloemendal, J., Deng, C.L., Song, Y., Ge, J.Y., Wu, H.B., Xu, B., Li, F.J., Han, L., Fu, Y., Guo, Zhengtang, 2018. The different climatic response of pedogenic hematite and ferrimagnetic minerals: evidence from particle-sized modern soils over the Chinese Loess Plateau. Quat. Sci. Rev. 179, 69-86.

Ge, Q.S., Liu, J., Fang, X.Q., Yang, B., Hao, Z.X., Shao, X.M., Zheng, J.Y., 2013a. General characteristics of temperature change and centennial warm periods during the past 2000 years. Acta Geograph. Sin. 68 (5), 579-592 (in Chinese with English abstract).

Ge, Q.S., Hao, Z.X., Zheng, J.Y., Shao, X.M., 2013b. Temperature changes over the past 2000 yr in China and comparison with the Northern Hemisphere. Clim. Past 9, $1153-1160$.
Ge, C., Zhang, W.G., Dong, C.Y., Dong, Y., Bai, X.X., Liu, J.Y., Hien, N.T.T., Feng, H., Yu, L.Z., 2015. Magnetic mineral diagenesis in the river dominated inner shelf of the East China Sea, China. J. Geophys. Res. Solid Earth 120 (7), 4720-4733.

Graham, N.E., Ammann, C.M., Fleitmann, D., Cobb, K.M., Luterbacher, J., 2011. Support for global climate reorganization during the "Medieval Climate Anomaly". Clim. Dynam. 37, 1217-1245.

Grimm, E.C., Maher Jr., L.J., Nelson, D.M., 2009. The magnitude of error in conventional bulk-sediment radiocarbon dates from central North America. Quat. Res. 72, 301-308.

Gu, Y.S., Liu, H.Y., Traoré, D.D., Huang, C.J., 2020. ENSO-related droughts and ISM variations during the last millennium in tropical southwest China. Clim. Dynam. 54, 649-659.

Hao, Q., Guo, Z., 2005. Spatial variations of magnetic susceptibility of Chinese loess for the last 600 kyr: implications for monsoon evolution. J. Geophys. Res. Solid Earth 110 (B12101). https://doi.org/10.1029/2005JB003765.

He, X.B., Zhang, X.B., Walling, D.E., 2005. The basin erosion rate calculation model based on deposit profile 137Cs changes of lake and reservoir. Prog. Nat. Sci. 15 (4), 495-498 (in Chinese with English abstract).

He, M., Yang, B., Bräuning, A., Wang, J., Wang, Z., 2013. Tree-ring derived millennial precipitation record for the south-central Tibetan Plateau and its possible driving mechanism. The Holocene 23, 36-45.

Hou, J., D'Andrea, W.J., Liu, Z., 2012. The influence of 14C reservoir age on interpretation of paleolimnological records from the Tibetan Plateau. Quat. Sci. Rev. 48, 67-79.

Hu, S.Y., Goddu, S.R., Herb, C., Appel, E., Gleixner, G., Wang, S.M., Yang, X.D., Zhu, X. H., 2015. Climate variability and its magnetic response in a lacustrine sequence in Heqing basin at the SE Tibetan Plateau since 900 ka. Geophys. J. Int. 201, 444-458.

Huang, Z.G., 1996. Red Weathering Crust in Southern China. Ocean Press, Beijing (In Chinese).

Kruiver, P.P., Dekkers, M.J., Heslop, D., 2001. Quantification of magnetic coercivity components by the analysis of acquisition curves of isothermal remanent magnetisation. Earth Planet. Sci. Lett. 189, 269-276.

Kumar, K.K., Rajagopalan, B., Hoerling, M., Bates, G., Cane, M., 2006. Unraveling the mystery of Indian monsoon failure during El Nino. Science 314, 115-119.

Lamb, H.H., 1977. Climate: Present, Past and Future (2), Climatic History and the Future, 59(6). Methuen, London, pp. 831-837.

Li, T., Zhang, Y., Chang, C.P., Wang, B., 2001. On the relationship between Indian Ocean sea surface temperature and Asian summer monsoon. Geophys. Res. Lett. 28, 2843-2846.

Lin, Q., Liu, E.F., Zhang, E.L., Shen, J., Yuan, H.Z., Wang, R., 2017. Temporal and spatial variations in sedimentary characteristics of Lake Lugu during the last hundred years and the influence factors analysis. J. Lake Sci. 29 (1), 246-256 (in Chinese with English abstract).

Lin, Q., Liu, E.F., Zhang, E.L., Nath, B., Shen, J., Yuan, H.Z., Wang, R., 2018. Reconstruction of atmospheric trace metals pollution in Southwest China using sediments from a large and deep alpine lake: historical trends, sources and sediment focusing. Sci. Total Environ. 613-614, 331-341.

Lise-Pronovost, A., St-onge, G., Gogorza, C., Jouve, G., Francus, P., Zolitschka, B., the PASADO Science Team, 2014. Rock-magnetic signature of precipitation and extreme runoff events in south-eastern Patagonia since 51,200 cal BP from the sediments of Laguna Potrok Aike. Quat. Sci. Rev. 98, 110-125.

Liu, Q.S., Deng, C.L., 2009. Magnetic susceptibility and its environmental significances. Chin. J. Geophys. 52 (4), 1041-1048 (in Chinese with English abstract).

Liu, J.B., Chen, F.H., Chen, J.H., Xia, D.S., Xu, Q.H., Wang, Z.L., Li, Y., 2011. Humid Medieval Warm Period recorded by magnetic characteristics of sediments from Gonghai Lake, Shanxi, North China. Chin. Sci. Bull. 56 (23), 2464-2474.

Liu, Q.S., Roberts, A.P., Larrasoaña, J.C., Banerjee, S.K., Guyodo, Y., Tauxe, L., Oldfield, F., 2012. Environmental magnetism: principles and applications. Rev. Geophys. 50, RG4002 https://doi.org/10.1029/2012RG000393.

Liu, C.C., Dupont-Nivet, G., Wang, W., Deng, C.L., 2021. Magnetic response to pedogenesis in aerobic soils of different weathering degree. Palaeogeogr. Palaeoclimatol. Palaeoecol. 567, 110240.

Ma, M.M., Hu, S.Y., Cao, L.W., Appel, E., Wang, L.S., 2014. Magnetic responses to traffic related contamination recorded by backfills: a case study from Tongling City, China. J. Appl. Geophys. 107, 119-128.

Ma, M.M., He, M., Liu, X.M., Chen, B.L., 2020. How long does iron oxide dissolution and transformation require under water-logged conditions? - a perspective from agricultural activity. Earth Planet. Sci. Lett. 531, 115958.

Maher, B.A., 2007. Environmental magnetism and climate change. Contemp. Phys. 48, 247-274.

Nowaczyk, N.R., Harwart, S., Melles, M., 2001. Impact of early diagenesis and bulk particle grain size distribution on estimates of relative geomagnetic palaeointensity variations in sediments from Lama Lake, northern Central Siberia. Geophys. J. Int. $145,300-306$.

Oldfield, F., 1994. Toward the discrimination of fine-grained ferrimagnets by magnetic measurements in lake and near-shore marine sediments. J. Appl. Geophys. 99, 9045-9050.

Pan, Y.X., Zhu, R.X., Banerjee, S.K., Gill, J., Williams, Q., 2000. Rock magnetic properties related to thermal treatment of siderite: behavior and interpretation. J. Geophys. Res. 105 (B1), 783-794.

Peters, C., Austin, W.E.N., Walden, J., Hibbert, F.D., 2010. Magnetic characterisation and correlation of a Younger Dryas tephra in North Atlantic marine sediments. J. Quat. Sci. 25, 339-347.

Reimer, P.J., Bard, E., Bayliss, A., Beck, J.W., Blackwell, P.G., Ramsey, C.B., Buck, C.E., Cheng, H., Edwards, R.L., Friedrich, M., 2013. IntCal13 and Marine13 radiocarbon age calibration curves 0-50,000 years cal BP. Radiocarbon 55, 1869-1887. 
Roberts, A.P., 2015. Magnetic mineral diagenesis. Earth-Sci. Rev. 151, 1-47.

Sano, M., Ramesh, R., Sheshshayee, M.S., Sukumar, R., 2011. Increasing aridity over the past 223 years in the Nepal Himalaya inferred from a tree-ring 8180 chronology. Holocene 22, 809-817.

Sheng, E.G., Yu, K.K., Xu, H., Lan, J.H., Liu, B., Che, S., 2015. Late Holocene Indian summer monsoon precipitation history at Lake Lugu, northwestern Yunnan Province, southwestern China. Palaeogeogr. Palaeoclimatol. Palaeoecol. 438, 24-33.

Snowball, I.F., 1993. Geochemical control of magnetite dissolution in subarctic lake sediments and implication for environment magnetism. J. Quat. Sci. 8, 339-346.

Su, Y.L., Gao, X., Liu, Q.S., Wang, J.B., Haberzettl, T., Zhu, L.P., Li, J.H., Duan, Z.Q., Tian, L.D., 2013. Mineral magnetic study of lacustrine sediments from Lake Pumoyum Co, southern Tibet, over the last $19 \mathrm{ka}$ and paleoenvironmental significance. Tetonophysics 588, 209-221.

Tan, L., Cai, Y., Yi, L., An, Z., Ai, L., 2008. Precipitation variations of Longxi, northeast margin of Tibetan Plateau since AD 960 and their relationship with solar activity. Clim. Past 4, 19-28.

Tan, L.C., Cai, Y.J., Chen, H., Edwards, L.R., Lan, J.H., Zhang, H.W., Li, D., Ma, L., Zhao, P.P., Gao, Y.L., 2018. High resolution monsoon precipitation changes on southeastern Tibetan Plateau over the past 2300 years. Quat. Sci. Rev. 195, 122-132.

Tan, L.C., Shen, C.C., Löwemark, L., Chawchai, S., Edwards, R.L., Cai, Y.J., Breitenbach, S.F.M., Cheng, H., Chou, Y.C., Duerrast, H., Partin, J.W., Cai, W.J., Chabangborn, A., Gao, Y.L., Kwiecien, O., Wu, C.C., Shi, Z.G., Hsu, H.H., Wohlfarth, B., 2019. Rainfall variations in central Indo-Pacific over the past 2,700 y. Proc. Natl. Acad. Sci. https://doi.org/10.1073/pnas.1903167116.

Thompson, R., Oldfeld, F., 1986. Environmental Magnetism. Allen and Unwin, London.

Wang, B., 2006. The Asian Monsoon. Springer, Chichester.

Wang, S., Dou, H., 1998. Lakes in China. Science Press, Beijing (in Chinese).

Wang, B., Wu, R., Fu, X., 2000. Pacific-East Asian teleconnection: how does ENSO affect East Asian climate? J. Clim. 13, 1517-1536.

Wang, H.Y., Xu, L., Sun, X.B., Lu, M.H., Du, X.Y., Huo, Y.Y., Snowball, I., 2011. Comparing mineral magnetic properties of sediments in two reservoirs in "strongly" and "mildly" eroded regions on the Guizhou Plateau, southwest China: a tool for inferring differences in sediment sources and soil erosion. Geomorphology 130 (3-4), 255-271.

Wang, L.S., Hu, S.Y., Yu, G., Ma, M.M., Liao, M.N., 2015. Paleoenvironmental reconstruction of the radial sand ridge field in the South Yellow Sea (east China) since $45 \mathrm{ka}$ using the sediment magnetic properties and granulometry. J. Appl. Geophys. 122, 1-10.

Wang, L.S., Hu, S.Y., Ma, M.M., Wang, X.H., Wang, Q., Zhang, Z.H., Shen, J., 2018a. Responses of magnetic properties to heavy metal pollution recorded by lacustrine sediments from the Lugu Lake, Southwest China. Environ. Sci. Pollut. Res. 25, 26527-26538.

Wang, L.S., Hu, S.Y., Yu, G., Ma, M.M., Wang, Q., Zhang, Z.H., Liao, M.N., Gao, L., Ye, L. T., Wang, X.H., 2018b. Magnetic characteristics of sediments from a radial sand ridge field in the South Yellow Sea, eastern China, and environmental implications during the mid- to late-Holocene. J. Asian Earth Sci. 163, 224-234.

Wang, Y.B., Zhang, E.L., Sun, W.W., Chang, J., Liu, X.Q., Ni, Z.Y., Ning, D.L., 2019. Holocene evolution of the Indian Summer Monsoon inferred from a lacustrine record of Lake Wuxu, south-east Tibetan Plateau. J. Quat. Sci. 34 (6), 463-474.

Wang, Q., Anderson, N.J., Yang, X.D., Xu, M., 2020. Interactions between climate change and early agriculture in SW China and their effect on lake ecosystem functioning at centennial timescales over the last 2000 years. Quat. Sci. Rev. 233, 106238.

Wei, Z.Q., Zhong, W., Shang, S.T., Ye, S.S., Tang, X.W., Xue, J.B., Ouyang, J., Smol, J.P., 2018. Lacustrine mineral magnetic record of postglacial environmental changes from Dahu Swamp, southern China. Glob. Planet. Chang. 170, 62-75.

Wu, W., Liu, T., 2004. Possible role of the "holocene event 3" on the collapse of Neolithic Cultures around the central plain of China. Quat. Int. 117, 153-166.

Xu, H., Song, Y.P., Goldsmith, Y., Lang, Y.C., 2019. Meridional ITCZ shifts modulate tropical/subtropical Asian monsoon rainfall. Sci. Bull. 64, 1737-1739.

Xu, X.W., Qiang, X.K., Zhao, H., Fu, C.F., 2020. Magnetic mineral dissolution recorded in a lacustrine sequence from the Heqing Basin, SW China, and its relationship with changes in the Indian monsoon. J. Asian Earth Sci. 188, 104081.

Yan, H., Sun, L., Wang, Y., Huang, W., Qiu, S., Yang, C., 2011. A record of the Southern Oscillation Index for the past 2,000 years from precipitation proxies. Nat. Geosci. 4, 611-614.

Zhang, S., Xie, X., Wan, G., 1997. Mineralogical records and their environmental aspects of Lugu Lake, Yunnan Province. Acta Mineral. Sin. 17, 183-193 (in Chinese with English abstract).

Zhang, P., Cheng, H., Edwards, R.L., Chen, F., Wang, Y., Yang, X., Liu, J., Tan, M., Wang, X., Liu, J., An, C., Dai, Z., Zhou, J., Zhang, D., Jia, J., Jin, L., Johnson, K.R., 2008. A test of climate, sun, and culture relationships from an 1810-year Chinese cave record. Science 322, 940-942.

Zhang, E.L., Tang, H.Q., Cao, Y.M., Langdon, P., Wang, R., Yang, X.D., Shen, J., 2013. The effects of soil erosion on chironomid assemblages in Lugu Lake over the past 120 years. Int. Rev. Hydrobiol. 98 (3), 165-172.

Zhao, W.L., Xie, S.J., 1988. History of Population in China. People's Publishing House.

Zheng, J., Wang, W., Ge, Q., Man, Z., Zhang, P., 2006. Precipitation variability and extreme events in eastern China during the past 1500 years. Terr. Atmos. Ocean. Sci. 17, 579-592. 